\title{
Novel and Very Compact Reconfigurable Bandpass to Lowpass/Bandpass Microstrip Filter with Wide- stopband Restriction for 5G Communications
}

\author{
Yasir I. A. Al-Yasir ${ }^{1}$, Y. Tu ${ }^{1}$, Naser Ojaroudi Parchin ${ }^{1}$, Ahmed Abdulkhaleq ${ }^{1,2}$, Jamal \\ Kosha $^{1}$, Widad A Mshwat ${ }^{1}$, Embarak M. I. Elfoghi ${ }^{3}$, Hassan Migdadi ${ }^{4}$, Raed Abd-Alhameed ${ }^{1,5}$ \\ \{Y.I.A.Al-Yasir@bradford.ac.uk\} \\ ${ }^{1}$ Faculty of Engineering and Informatics, University of Bradford, Bradford, UK \\ ${ }^{2}$ SARAS Technology, Leeds, UK \\ ${ }^{3}$ College of Electronic Technology, Bani Walid, Libya \\ ${ }^{4}$ Greater Amman Municipality, Jordan \\ ${ }^{5}$ Information and Communication Eng. Department, Basrah University College of Science and \\ Technology, Basrah 24001, Iraq
}

\begin{abstract}
This paper presents a novel and very compact planer reconfigurable bandpass to bandpass/lowpass filter covering the 0 to $1 \mathrm{GHz}$ and 3.4 to $3.8 \mathrm{GHz}$ spectrum for $5 \mathrm{G}$ applications. The microstrip filter employs three open-loop ring resonators with $50 \Omega$ tapped lines for input and output ports. To achieve sharper cut-off frequencies, finite transmission zeros are successfully generated on the upper and lower edges of the 5G passbands. By utilization of the forth resonator between the input and output ports, Lowpass characteristics and reconfigurability properties are achieved. The cross-coupling coefficients between the resonators are optimized to resonate at the required frequency with proper bandwidth. The reported filter is simulated and optimized using CST software, and is designed on a Rogers RO3010 substrate with a relative dielectric constant of 10.2 and a very compact size of $10 \times 7.9 \times 1.27 \mathrm{~mm}^{3}$.
\end{abstract}

Keywords: Microstrip filter, bandpass, open-loop, 5G, compact, CST.

\section{Introduction}

RF noise is a serious concern in recent applications of wireless communications such as green communications and wide-band radar systems [1-18]. Planer bandpass filter is commonly employed to suppress noise and undesirable signals in different communication systems [19], basically in RF and microwave communications because of their effective rejection of harmonic signals. Currently, $5 \mathrm{G}$ application technologies are being utilized for use in $700 \mathrm{MHz}, 3.6 \mathrm{GHz}$ and $26 \mathrm{GHz}$ spectrums [20]. BPFs must fulfill specific requirements in 5G applications [21- 23]. A BPF consists of a number of coupled elements and resonators, and the sizes of the distributed lines describes the filter specifications and performance. In addition, most planer design miniaturization techniques try to reduce these factors.

Different designs and methodologies have been presented for planer microwave filters such as combline, hairpin, parallel-coupled line, step impedance, and stub impedance [24-31]. A planer structure with Chebyshev characteristics is presented for a $2.44 \mathrm{GHz}$ mid-band frequency 
with $0.55 \mathrm{~dB}$ ripple factor. The obtained insertion loss is less than $1.1 \mathrm{~dB}$ and return loss is greater than $13 \mathrm{~dB}$ [24]. In [26], a small size microstrip PBF was proposed by using a novel transmission coupled line method. Two microstrip transmission lines of three parallel-coupled sections, a quarter wavelength long, was utilized to build a band-pass filter with a mid-band frequency of $2.8 \mathrm{GHz}$. Non-Uniform elements are used to separate the two transmission lines, and the size of the structure was $20.5 \times 7.5 \mathrm{~mm}^{2}$. Another technique in [27] used low temperature co-fired ceramic (LTCC) structure, whose fabrication is realized by utilizing the reliable electromagnetic investigation, resulting in proper filter designs with a very compact size. Microstrip hairpin structures can be employed to design a compact size band-pass planer filters. The analysis of these structures employs a variable coupling across the hairpin resonators with T-feeders [28]. For this design, the measurement results of mid-band resonant frequency is shifted down by roughly about $0.3 \mathrm{GHz}$ compared with the simulation results. The resonant frequency is $5.7 \mathrm{GHz}$ necessary for RFID wireless communications. The size of the proposed band-pass filter is about $26 \times 12 \mathrm{~mm}^{2}$. From the other side, Combline band-pass filter structures, with the merit of compact size and low loss, are usually preferred in today wireless communications [29, 30]. In [29], a novel implemented Combline BPF is proposed with two transmission zeros, two poles, and physical dimensions of $27.4 \times 5.5 \mathrm{~mm}^{2}$. The operation frequency for the reported filter is 1.45 $\mathrm{GHz}$ with a $-3 \mathrm{~dB}$ fractional bandwidth (FBW) of about $12 \%$, insertion loss $2.8 \mathrm{~dB}$ and passband return loss $18.5 \mathrm{~dB}$. An improved combline BPF with an array of stepped-impedance (SIRs) is proposed and implemented in [30]. The filter has the advantage of few via-hole grounds which is recommended by multilayer planer structures. Same design can be modified with 4th order $\mathrm{BPF}$ and will have a return loss and the insertion loss greater than $16 \mathrm{~dB}$ and less than $1.8 \mathrm{~dB}$ respectively, all by using a microstrip structure with physical dimensions $12.5 \times 10 \mathrm{~mm}^{2}$.

From the other side, some wireless communication systems of microstrip filters demand a high selectivity on only one edge of the passband, but less or none on the other edge. Therefore, employing a design with asymmetric frequency response will be required [16]. This is due to the fact that a symmetric frequency characteristics designs will lead to a high number of resonators, high insertion loss, larger size and a high cost circuits.

This article presents a very compact 4-pole reconfigurable microstrip filter with Lowpass and bandpass frequency response, simulated using CST software tool to operate with the frequency bands of 0 to $1 \mathrm{GHz}$ and 3.4 to $3.7 \mathrm{GHz}$, and suitable for $5 \mathrm{G}$ communications. The proposed foursection reconfigurable bandpass to bandass/lowpass filter is designed on a Rogers RO3010 substrate with a relative dielectric constant of 10.2 and a very compact size of $10 \times 7.9 \times 1.27 \mathrm{~mm}^{3}$. In addition, it is worthy to say that this design can be easily integrated with the antenna structure [32], to accomplish the so-called "filtenna" [35]. The proposed open-loop microstrip BPF and its simulation and measurement results are analyzed and explained in the following sections.

\section{Three-pole filter}

The design steps of the reported BPF can be summarized with the following procedure: Step 1) Design a low-pass filter (LPF) prototype with normalized characteristics impedance (g0) and cut-off frequency $(\Omega \mathrm{c})$.

Step 2) Using some transformation techniques to convert the designed low-pass filter prototype to the band-bass filter operating on the required resonant frequency. This step will resulting in a band-pass filter with a lumped-elements circuit consists of a capacitors and inductors.

Step 3) Richards' transformation can be applied to transform the band-pass filter into a microstrip planer band-pass filter [16]. 


\subsection{Low-Pass Filter (LPF) Prototype}

A three-order lumped element LPF prototype is presented on this step. The filter is resonating on $3.6 \mathrm{GHz}$ with FBW $11 \%$ and low ripple factor. The equivalent circuit of the prototype filter with order $n$ is shown in Fig. 1 with LPF prototype parameters $g_{i}$ for $i=0$ to $n+1$. According to [16], The LPF with Butterworth characteristics can be employed to compute the values of $\mathrm{g}_{\mathrm{i}}$ to give: $\mathrm{g}_{0}=\mathrm{g}_{4}=1 \mathrm{v}, \mathrm{g}_{1}=\mathrm{g}_{3}=1 \mathrm{H}$ and $\mathrm{g}_{2}=2 \mathrm{~F}$ for cut-off frequency $\Omega_{\mathrm{c}}=1 \mathrm{rad} / \mathrm{s}$.

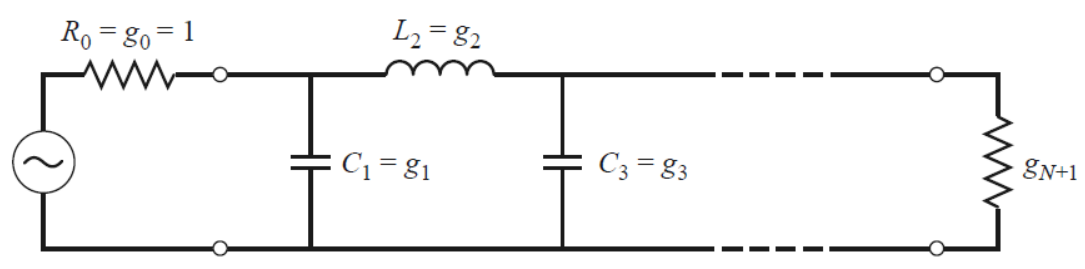

Fig. 1. A ladder circuit of the prototype LPF.

\subsection{Design of L-C Circuit of the proposed filter}

Frequency and element transformation techniques can be applied to obtain the lumpedelement circuit of the BPF from the designed LPF prototype (which has a normalized characteristic impedance $\mathrm{g}_{0}=1$ and $\Omega_{\mathrm{c}}=1.0 \mathrm{rad} / \mathrm{s}$ ). The angular frequency conversion affects just the reactive elements and has no effect on the resistive elements. The angular cut-off frequency and the impedance scaling factor are $2 \pi \times 3.6 \times 10^{9} \mathrm{rad} / \mathrm{s}$ and $\gamma_{0}=50$ respectively. From [16], we find $\mathrm{L}_{1}=\mathrm{L}_{3}=22 \mathrm{nH}, \mathrm{L}_{2}=0.15 \mathrm{nH}, \mathrm{C}_{1}=\mathrm{C}_{3}=0.1 \mathrm{pF}$ and $\mathrm{C}_{2}=18 \mathrm{pF}$. As a result, and according to the procedure detailed above, we can get the equivalent circuit of the lumpedelement BPF as shown in Fig. 2.

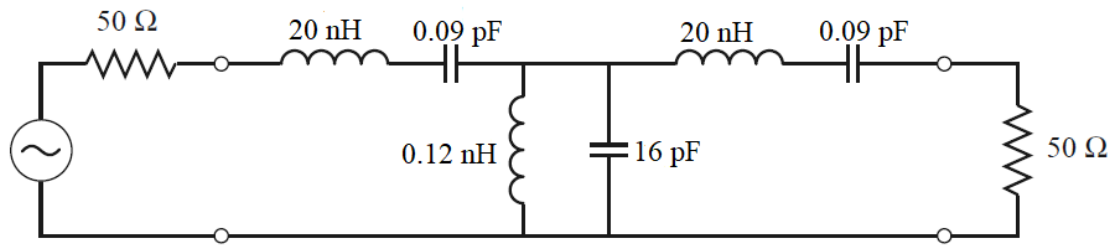

Fig. 2. Equivalent circuit of the lumped-element BPF.

\subsection{Design of the third order planar filter}

According to [16], Richards' transformations [16] are applied to convert the designed lumped-element BPF designed into a transmission line model.

The geometry of the proposed cross-coupled BPF is shown in Fig. 3. Three open-loop ringresonators fed by two ports $50 \Omega$ input impedance minimize the physical size, eliminating the need for vias. The filter has a transmission line feed and uses Rogers RO3010 substrate, with $\mathrm{h}$ $=1.27 \mathrm{~mm}, \varepsilon_{r}=10.2$ and loss tangent $=0.0022$. The resonant frequency $3.6 \mathrm{GHz}$ is chosen as it is suitable for $5 \mathrm{G}$. 
The equivalent circuit of the trisection open-loop BPF can be performed as shown in Fig. 4. $\mathrm{M}_{12}$ and $\mathrm{M}_{23}$ denote the coupling coefficients between the adjacent resonators, and the cross coupling coefficient between the resonators 1 and 3 is represented by $\mathrm{M}_{13}$. The external quality factors for the input and output couplings are represented by $\mathrm{Q}_{\mathrm{ei}}$ and $\mathrm{Q}_{\mathrm{eo}}$, respectively. The angular frequency of resonator $\mathrm{n}$ is $\omega_{0 n}=2 \pi f_{0 n}=1 / \sqrt{ }\left(L_{n} C_{n}\right)$ for $\mathrm{n}=1,2$ and 3. To simplify the design, we can consider that $\mathrm{M}_{12}=\mathrm{M}_{23}, \mathrm{Q}_{\mathrm{e} 1}=\mathrm{Q}_{\mathrm{e} 3}$ and $\omega_{01}=\omega_{03}$. For the proposed filter, it can be seen the cross coupling between resonators 1 and 3 is positive $\left(\mathrm{M}_{13}>0\right)$, and this denotes that the attenuation pole of finite frequency is on the upper edge of the pass-band. The physical parameters of the planer 3-pole filter can be calculated by employing the same design steps detailed in [16]. The configuration of the BPF filter and its optimized parameters are shown in Fig. 3 and Table 1, respectively. In addition, the dimensions of the proposed BPF is about 0.27 $\lambda_{\mathrm{g} 0} \times 0.17 \lambda_{\mathrm{g} 0}$, where $\lambda_{\mathrm{g} 0}$ represents the guided wavelength of a $50 \Omega$ transmission line on the substrate at the resonant frequency $3.6 \mathrm{GHz}$.

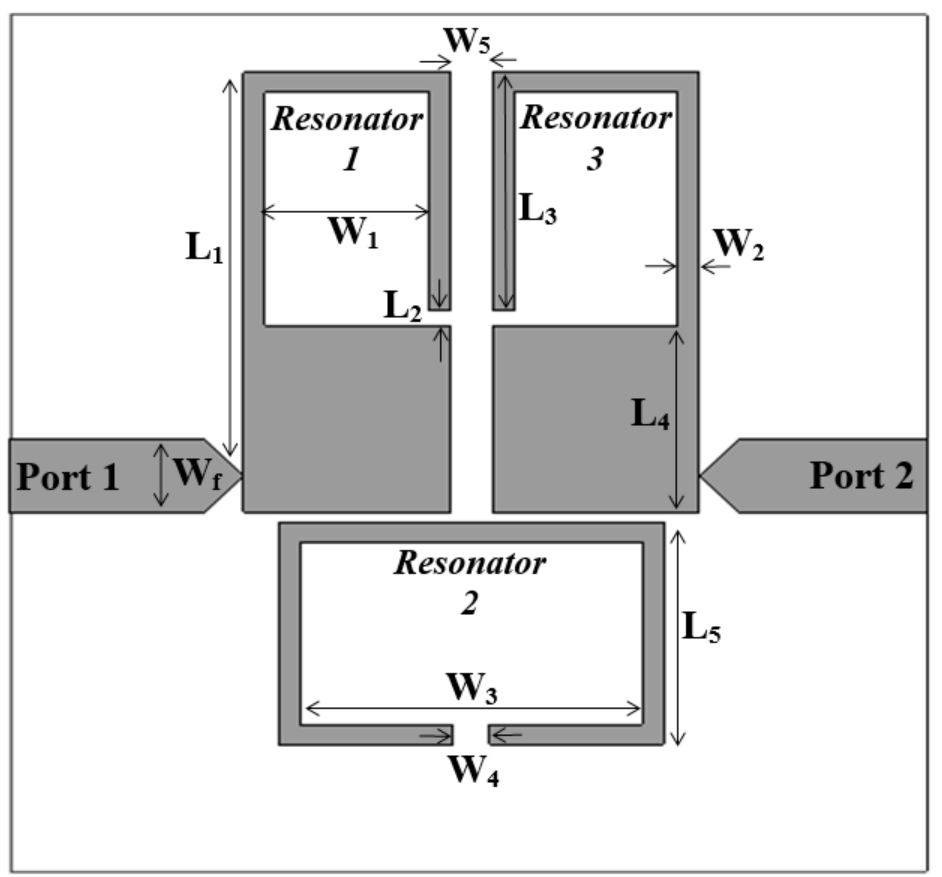

Fig. 3. Geometry of the introduced planar filter. 


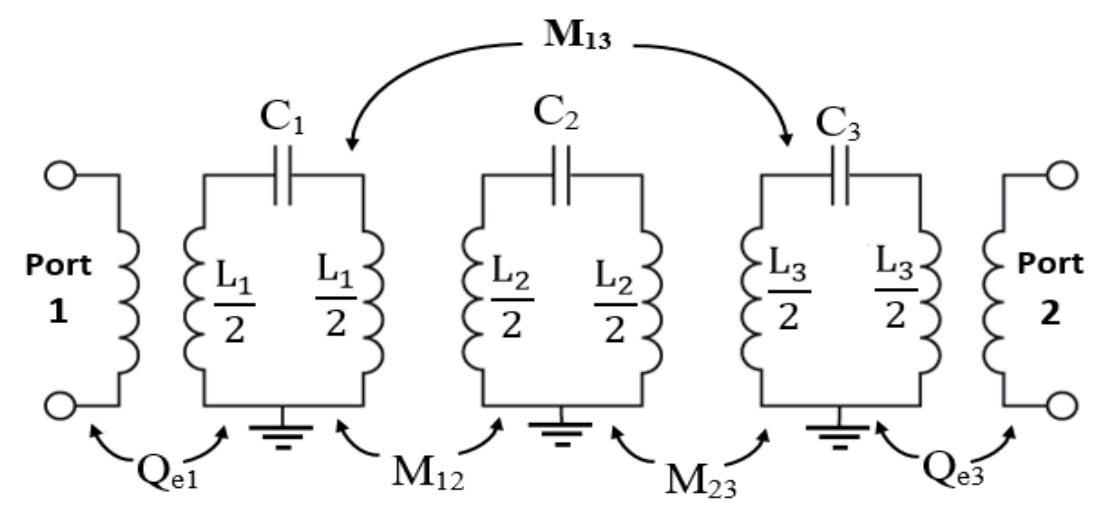

Fig. 4. L-C circuit of the planar filter.

Table 1. The optimized dimensions of the proposed cross-coupled planar filter.

\begin{tabular}{cc}
\hline Parameter & Value (mm) \\
\hline $\mathrm{L}_{1}$ & 5.98 \\
$\mathrm{~L}_{2}$ & 0.3 \\
$\mathrm{~L}_{3}$ & 3.3 \\
$\mathrm{~L}_{4}$ & 3.0 \\
$\mathrm{~L}_{5}$ & 3.4 \\
$\mathrm{~W}_{1}$ & 2.4 \\
$\mathrm{~W}_{2}$ & 0.28 \\
$\mathrm{~W}_{3}$ & 5.0 \\
$\mathrm{~W}_{4}$ & 0.6 \\
$\mathrm{~W}_{5}$ & 0.59 \\
$\mathrm{~W}_{\mathrm{f}}$ & 1.08 \\
\hline
\end{tabular}

Fig. 5 shows the simulated results of the return loss and the insertion loss of the designed 3 pole BPF. The simulation results show that the proposed filter has insertion loss of $0.8 \mathrm{~dB}$ across the pass-band with return loss better than $30 \mathrm{~dB}$. Moreover, and to increase the selectivity of the pass-band, two transmission zeros have been successfully generated in the upper edge of the pass-band. 


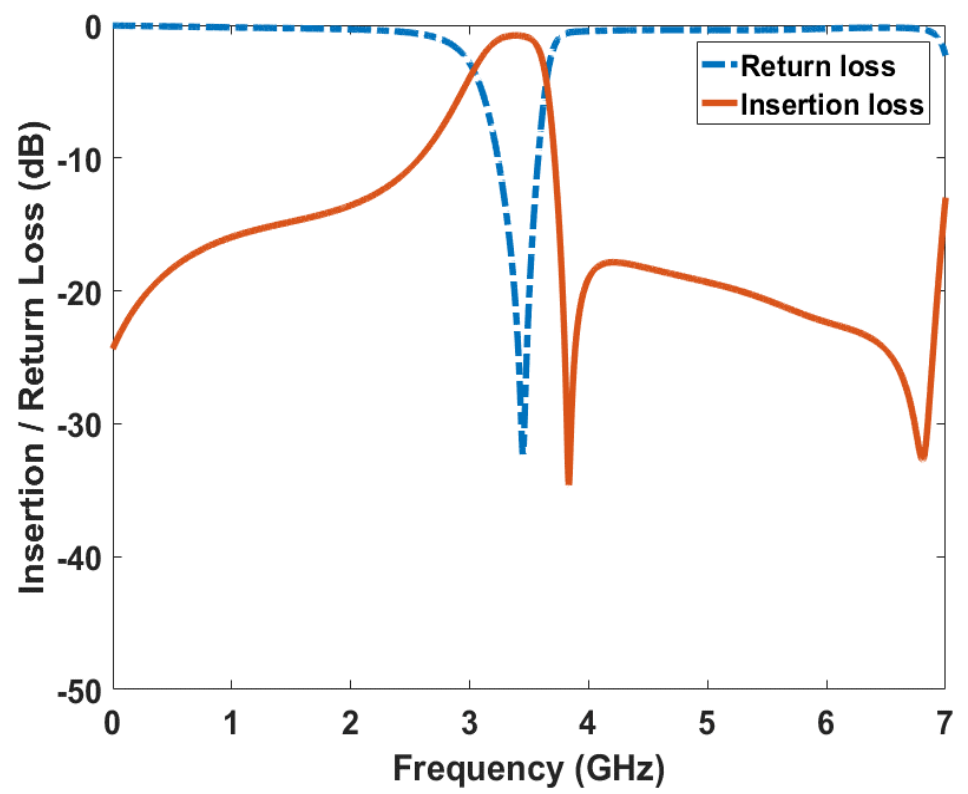

Fig. 5. S-parameter performance for the 3-pole BPF.

\section{4-Pole reconfigurable filter}

To achieve the lowpass characteristics and the reconfigurability property, resonator 4 (R4) is added to the 3-pole BPF. The length of the resonator is selected to be $\lambda_{\mathrm{g} g} / 2=20 \mathrm{~mm}$ and 0.35 $\mathrm{mm}$ width, where $\lambda_{\mathrm{g} 0}$ here represents the guided wavelength at the resonant frequency. Fig. 6 shows the configuration of the designed 4-pole reconfigurable microstrip filter. Obviously, the size of the designed filter is very compact with merit of reconfigurability. The optimized parameters are obtained by using the trust region framework algorithm embedded with the CST software as detailed in Table 1. Fig. 7(a) shows the s-parameter results of the return loss and the insertion loss of the designed microstrip filter in the off-state configuration for tackling the single-band bandpass characteristics. The simulation results show that the proposed BPF has insertion loss of $0.8 \mathrm{~dB}$ at the resonant frequency $3.5 \mathrm{GHz}$, with return loss better than $20 \mathrm{~dB}$. Fig. 7(b) shows the s-parameter results of the return loss and the insertion loss of the designed dual-band filter in the on-state configuration for tackling the lowpass and bandpass filter characteristics. At the resonant frequency $700 \mathrm{MHz}$, the simulation results of the first passband show that the proposed filter has insertion loss of $0.07 \mathrm{~dB}$ with return loss better than $20 \mathrm{~dB}$ for the low pass filter configuration. From the other hand, at the resonant frequency $3.5 \mathrm{GHz}$, the performance of the second passband show that the proposed filter has insertion loss of $0.5 \mathrm{~dB}$ with return loss better than $30 \mathrm{~dB}$ for the bandpass filter configuration. Moreover, and to increase the selectivity of the pass-band, some of finite transmission zeros have been successfully generated in the upper/lower edges of the pass band as shown in Fig. 8 . 


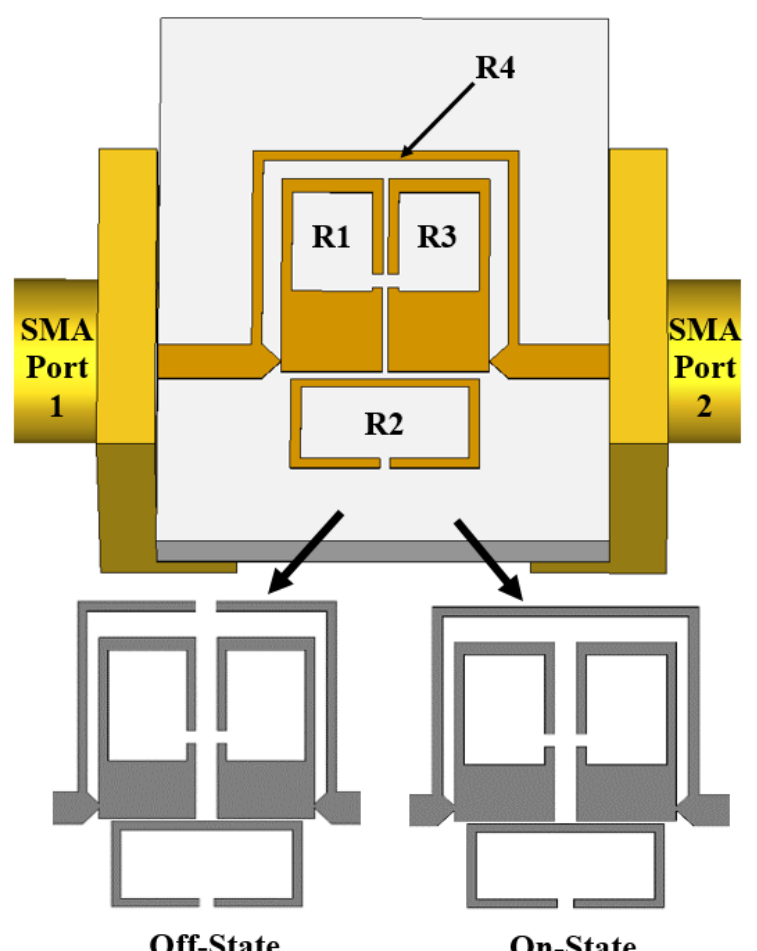

Fig. 6. The geometry of the reconfigurable microstrip filter and the on-off states configurations.

Fig. 8 shows the frequency response of the group delay and the phase of $S_{21}$ for the designed microstrip filter for both configurations (on and off states). As seen in this figure, the maximum in-band group-delay ( $\tau \mathrm{g}$ ) variations are around $1 \mathrm{~ns}$ for the both configurations of the reconfigurable filter. The proposed 4-pole cross-coupled band pass filter has a number of attractive properties, which include: (1) The proposed design is very compact in size and simply structured. (2) Good stopband rejection and selectivity have achieved. (3) The measured insertion loss is very low with good return loss and group delay to cover the $4 \mathrm{G}(2.5-2.6 \mathrm{GHz})$ and 5G (3.7-3.8GHz) spectrum. (4) Compared to the designed filters in [21], [23], [31] and [32], the proposed filter has smaller size and better performance with the merit of dual-band characteristics. 

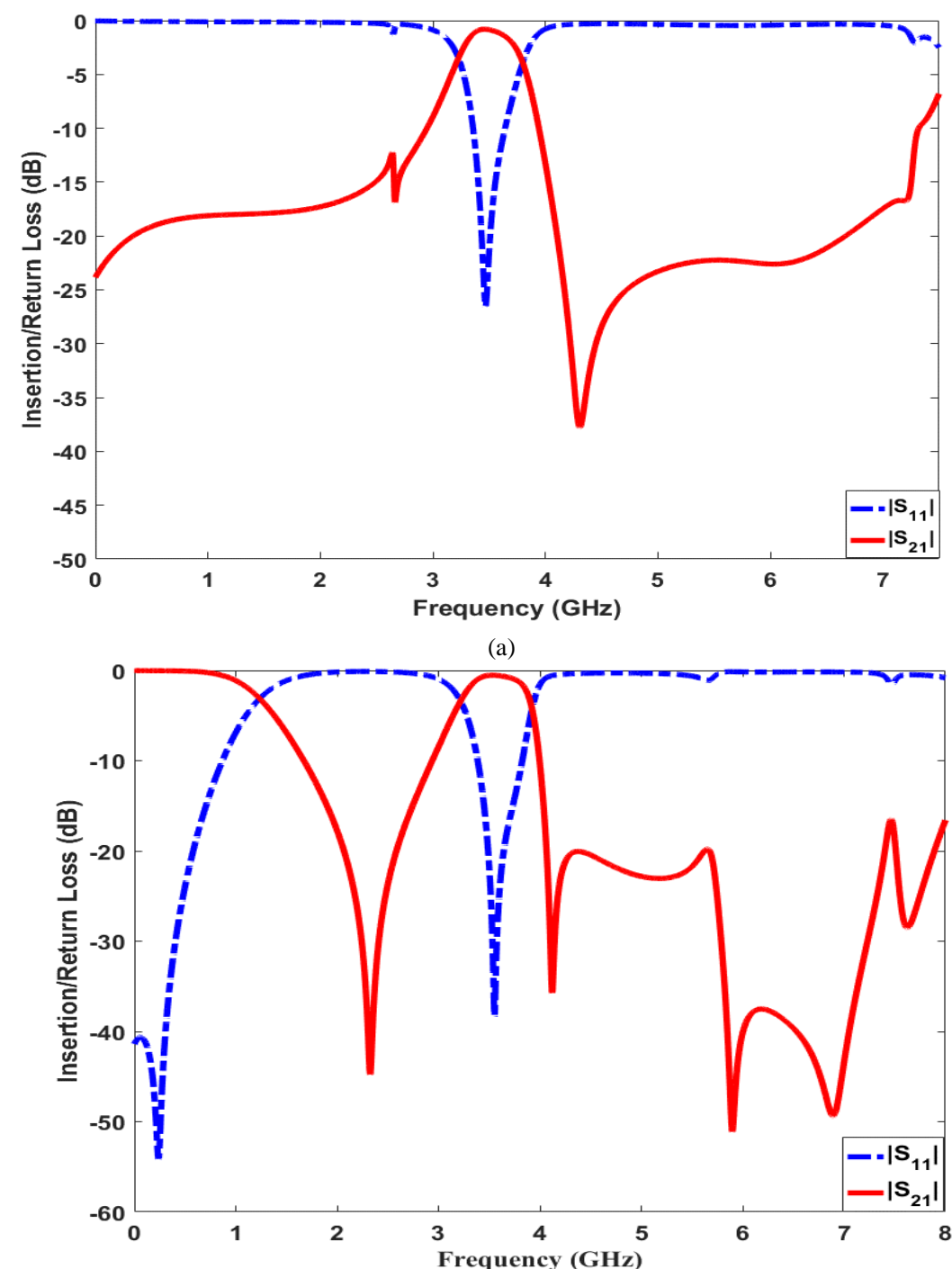

(b)

Fig. 7. Insertion/return loss performance for the proposed filter: (a) off-state configuration. (b) on-state configuration. 


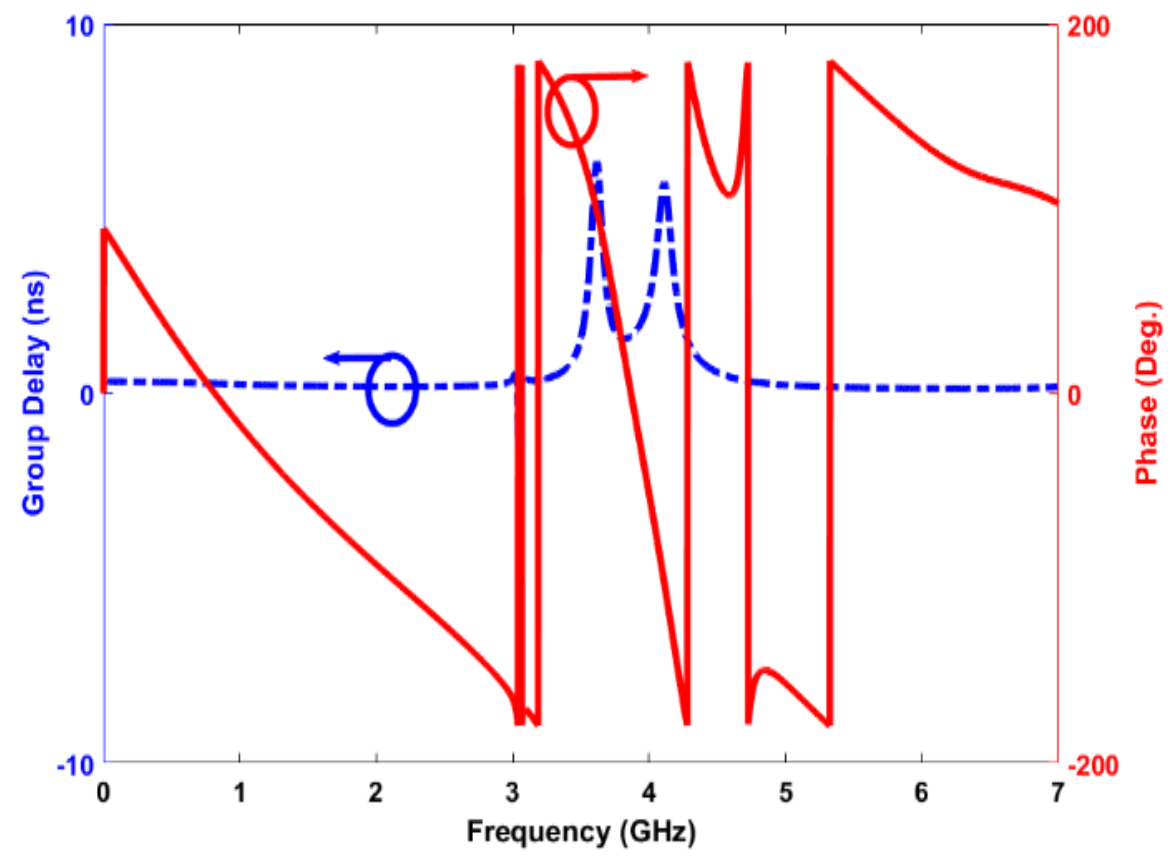

(a)

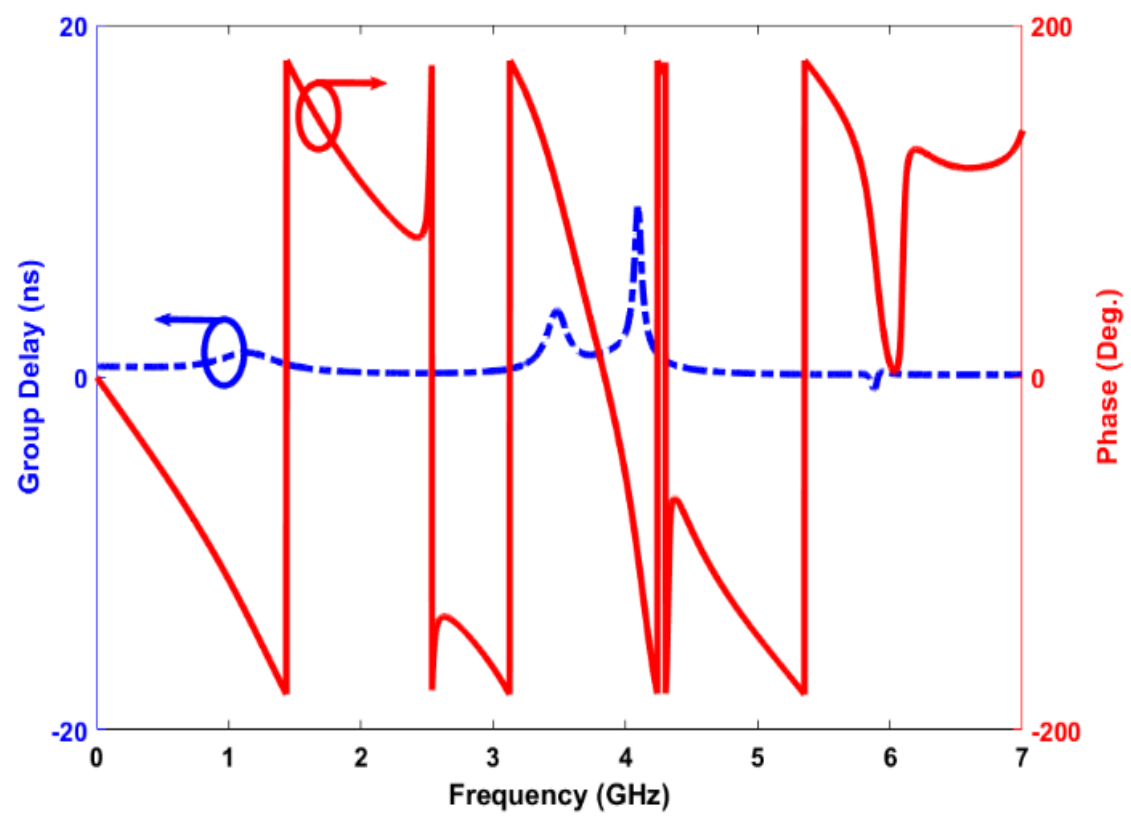

(b)

Fig. 8. Frequency response of the group delay and the phase of $S_{21}$ for the proposed filter: (a) off-state configuration. (b) on-state configuration. 


\section{Conclusion}

A novel and very compact reconfigurable microstrip bandpass and lowpass filter is presented in this paper to covering 0 to $1 \mathrm{GHz}$ and 3.4 to $3.8 \mathrm{GHz}$ spectrum for $5 \mathrm{G}$ applications. To achieve the lowpass characteristics and reconfigurability properties, forth resonator is utilized between the input and output ports for the reported filter. Finite transmission zeroes are successfully generated on the upper/lower edges of the passbands to increase the selectivity of the proposed reconfigurable filter.

Acknowledgments. This project has received funding from the European Union's Horizon 2020 research and innovation programme under grant agreement H2020-MSCA-ITN-2016 SECRET-722424.

\section{References}

[1] A. Hussaini, Y. Al-Yasir, k. Voudouris, B. Mohammed, R. A. Abd-Alhameed, H. Mohammed, I. Elfergani, A. Abdullah, D. Makris, J. Rodriguez, J. M. Noras, C. Nche, and M. Fonkam, Green Flexible RF for 5G. Fundamentals of 5G Mobile Networks, John Wiley and Sons, pp. 241-272, 2015.

[2] Yasir I.A. Al-Yasir, Hasanain A.H. Al-Behadili, Baha A. Sawadi, Naser Ojaroudi Parchin, Ahmed M. Abdulkhaleq, Abdulkareem S. Abdullah and Raed A. Abd-Alhameed (September 26th 2019). New Radiation Pattern-Reconfigurable 60-GHz Antenna for 5G Communications, IntechOpen, Available from: https://www.intechopen.com/online-first/new-radiation-pattern-reconfigurable-60-ghzantenna-for-5g-communications.

[3] Y. Al-Yasir et al., "Compact tunable microstrip filter with wide-stopband restriction and wide tuning range for 4G and 5G applications," The IET's Antennas and Propagation Conference, 2019, pp. 1-6.

[4] Abdulraheem, Y., A. S. Abdullah, H. J. Mohammed, B. A. Mohammed, and R. A. Abd-Alhameed, "Design of radiation pattern-reconfigurable $60-\mathrm{GHz}$ antenna for $5 \mathrm{G}$ applications," Journal of Telecommunications, vol. 52, no. 4, pp. 1-5, 2014.

[5] H. J. Mohammed et al., "Evaluation of genetic algorithms, particle swarm optimisation, and firefly algorithms in antenna design," 2016 13th International Conference on Synthesis, Modeling, Analysis and Simulation Methods and Applications to Circuit Design (SMACD), Lisbon, 2016, pp. 1-4.

[6] Y. I. A. Al-Yasir and R. Abd-Alhameed, "New multi-standard dual-wideband and quad-wideband asymmetric step impedance resonator filters with wide stop band restriction," International Journal of RF and Microwave Computer-Aided Engineering, vol. 29, no. 8, p. 1-17, 2019.

[7] Y. I. A. AI-Yasir, N. Ojaroudi Parchin, A. Alabdullah, W. Mshwat, A. Ullah and R. Abd-Alhameed, "New pattern reconfigurable circular disk antenna using two PIN diodes for WiMax/WiFi (IEEE 802. 11 a) applications," 2019 16th International Conference on Synthesis, Modeling, Analysis and Simulation Methods and Applications to Circuit Design (SMACD), Lausanne, Switzerland, 2019, pp. 53-56.

[8] Y. I. A. Al-Yasir et al, "Design, simulation and implementation of very compact dual-band microstrip bandpass filter for 4G and 5G applications," 2019 16th International Conference on Synthesis, Modeling, Analysis and Simulation Methods and Applications to Circuit Design (SMACD), Lausanne, Switzerland, 2019, pp. 41-44.

[9] Y. I. A. Al-Yasir, N. O. Parchin, A. Alabdallah, A. M. Abdulkhaleq, R. A. Abd-Alhameed and J. M. Noras, "Design of Bandpass Tunable Filter for Green Flexible RF for 5G," 2019 IEEE 2nd 5G World Forum (5GWF), Dresden, Germany, 2019, pp. 194-198.

[10] Y. I. A. Al-Yasir et al., "Design, Simulation and Implementation of Very Compact Open-loop Trisection BPF for 5G Communications," 2019 IEEE 2nd 5G World Forum (5GWF), Dresden, Germany, 2019, pp. 189-193. 
[11] Y. Al-Yasir, A. S. Abdullah, N. Ojaroudi Parchin, R. A. Abd-Alhameed, and J. M. Noras, "A New Polarization-Reconfigurable Antenna for 5G Applications," Electronics, vol. 7, no. 11, p. 293, 2018.

[12] Al-Yasir Y.I.A. et al. (2019) A New Polarization-Reconfigurable Antenna for 5G Wireless Communications. In: Sucasas V., Mantas G., Althunibat S. (eds) Broadband Communications, Networks, and Systems. BROADNETS 2018. Lecture Notes of the Institute for Computer Sciences, Social Informatics and Telecommunications Engineering, vol 263. Springer, Cham.

[13] Y. I. A. Al-Yasir et al., "A Differential-Fed Dual-Polarized High-Gain Filtering Antenna Based on SIW Technology for 5G Applications," 2020 14th European Conference on Antennas and Propagation (EuCAP), Copenhagen, Denmark, 2020, pp. 1-5.

[14] Y. I. A. Al-Yasir et al., "Design of multi-standard single/tri/quint-wideband asymmetric steppedimpedance resonator filters with adjustable TZs," IET Microwaves, Antennas \& Propagation, vol. 13, no. 10, pp. 1637-1645, 14 Aug. 2019.

[15] Y. I. A. Al-Yasir et al., " New High-Gain Differential-Fed Dual-Polarized Filtering Microstrip Antenna for 5G Applications," 2020 14th European Conference on Antennas and Propagation (EuCAP), Copenhagen, Denmark, 2020, pp. 1-5.

[16] Al-Yasir, Y.I.A.; A. Alhamadani, H.; Kadhim, A.S.; Ojaroudi Parchin, N.; Saleh, A.L.; Elfergani, I.T.E.; Rodriguez, J.; Abd-Alhameed, R.A. Design of a Wide-Band Microstrip Filtering Antenna with Modified Shaped Slots and SIR Structure. Inventions 2020, 5, 11.

[17] Al-Yasir, Y.I.A.; Ojaroudi Parchin, N.; Abdulkhaleq, A.M.; Bakr, M.S.; Abd-Alhameed, R.A. A Survey of Differential-Fed Microstrip Bandpass Filters: Recent Techniques and Challenges. Sensors 2020, 20, 2356.

[18] Al-Yasir, Y.I.A.; Alkhafaji, M.K.; A. Alhamadani, H.; Ojaroudi Parchin, N.; Elfergani, I.; Saleh, A.L.; Rodriguez, J.; Abd-Alhameed, R.A. A New and Compact Wide-Band Microstrip Filter-Antenna Design for 2.4 GHz ISM Band and 4G Applications. Electronics 2020, 9, 1084.

[19] J.-S. G. Hong and M. J. Lancaster, Microstrip Filters for RF/Microwave, vol. 167, John Wiley and Sons, 2004.

[20] "Ofcom," 8 February 2017. [Online]. Available: https://www.ofcom.org.uk/.

[21] J. S. Jeon, S. T. Kang and H. S. Kim, "GA-optimized compact broadband CRLH band-pass filter using stub-inserted interdigital coupled lines," Journal of Electromagnetic Engineering and Science, vol. 15, no. 1, pp. 31-36, 2015.

[22] Y. Al-Yasir, N. Ojaroudi Parchin, R. Abd-Alhameed, A. Abdulkhaleq and J. Noras, "Recent Progress in the Design of 4G/5G Reconfigurable Filters" Electronics”, vol. 8, no. 1, Jan. 2019.

[23] C. X. Wang, F. Haider, X. Gao, X. H. You, Y. Yang, D. Yuan, H. Aggoune, H. Haas, S. Fletcher and E. Hepsaydir, "Cellular architecture and key technologies for $5 \mathrm{G}$ wireless communication networks," IEEE Commun. Mag., vol. 52, no. 2, pp. 122-130, 2014.

[24] S. Srivastava, R. K. Manjunath and P. Shanthi. "Design, simulation and fabrication of a microstrip bandpass filter" International Journal of Science and Engineering Applications, vol. 3, no. 5, pp.1-4, 2014.

[25] Y. Al-Yasir, Y. Tu, N. Ojaroudi Parchin, I. Elfergani, R. Abd-Alhameed, J. Rodriguez, J. Noras, "Mixed-coupling multi-function quint-wideband asymmetric stepped impedance resonator filter" Microw. and Opt. Tech. Lett. Vol. 61, no. 5, pp1181-1148, Jan. 2019.

[26] H. N. Shaman. "New S-band bandpass filter (BPF) with wideband passband for wireless communication systems" IEEE Microwave Component Letter, vo. 22, no. 5 pp. 242-244, 2012.

[27] M. R. Saad, Z. Ambak, R. Alias and A. Ibrahim. "Designing 5 GHz microstrip coupled line bandpass filter using LTCC technology" in Proc. IEEE International Conference on Electronic Design, pp. 1-4, Penang, 2008.

[28] R. K. Maharjan, and N. Y. Kim. "Microstrip bandpass filters using window hairpin resonator and Tfeeder coupling lines" Arabian Journal for Science and Engineering, vol 39, no. 5, pp. 3989-3997, 2014.

[29] S.-C. Lin, C.-H. Wang, Y.-W. Chen and C. H. Chen. "Improved Combline Bandpass Filter with Multiple Transmission Zeros” 2007 Asia-Pacific Microwave Conference, pp. 1-4, Bangkok, 2007. 
[30] Y.-M. Chen, S.-F. Chang, C.-C. Chang, and T.-J. Hung. "Design of stepped-impedance combline bandpass filters with symmetric insertion-loss response and wide stopband range" IEEE Transaction on Microwave Theory Technology, vol. 55, no. 10, pp. 2191-2199, Oct. 2007.

[31] Y. Al-Yasir, R. A. Abd-Alhameed, J. M. Noras, A. Abdulkhaleq and N. Ojaroudi Parchin, "Design of Very Compact Combline Band-Pass Filter for 5G Applications," Loughborough Antennas \& Propagation Conference, Loughborough, UK, 2018.

[32] Y. I. Abdulraheem, G. Oguntala, A. Abdullah, H. Mohammed, R. A. Abd-Alhameed and J. M. Noras. "Design of frequency reconfigurable multiband compact antenna using two PIN diodes for WLAN/WiMAX applications," IET Microwaves, Antennas and Propagation, vol. 11, no. 8, pp. 1098$1105,2017$.

[33] H. Atallah, A. Abdul Rahman, K. Yoshitomi and P. Pokharel. "Compact frequency reconfigurable filtennas using varactor loaded t-shaped and h-shaped resonators for cognitive radio applications," IET Micro., Anten. and Propag., vol. 10, no. 9, pp. 991-1001, 2016.

[34] Hong. J.-S. and Lancaster. M.J.: 'Theorv and exoeriment of novel microstrip slow-wave open-loop resonitor filter”, IEEE Trans., 1997, MTT45, (12), pp. 2358-2365.

[35] H.-W. Deng, F. Liu, T. Xu, L. Sun and Y.-F. Xue, “Compact and high selectivity dual-mode microstrip BPF with frequency-dependent source-load coupling,” Elect. Lett., vol. 54, pp. 219-221, Feb. 2018. 